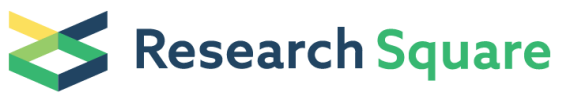 \\ Preprints are preliminary reports that have not undergone peer review. \\ They should not be considered conclusive, used to inform clinical practice, \\ or referenced by the media as validated information.
}

\section{Metabolic engineering of Escherichia coli for efficient production of L-alanyl-L-glutamine}

Jiangming Zhu ( $\nabla$ jmzhu0001@163.com)

Institute of Microbiology,Chiness Academy of Sciences,Beijing100101,China https://orcid.org/0000-0001-8996-2086

Wei Yang

Institute of Microbiology Chinese Academy of Sciences

\section{Bohua Wang}

Institute of Microbiology Chinese Academy of Sciences

\section{Qun Liu}

Institute of Microbiology Chinese Academy of Sciences\&University of Chinese Academy of Sciences

\section{Xiaotong Zhong}

Institute of Microbiology Chinese Academy of Sciences\&University of Chinese Academy of Sciences

\section{Quanxiu Gao}

Fujian Normal University

Jiezheng Liu

Institute of Microbiology Chinese Academy of Sciences\&University of Chinese Academy of Sciences

Jianzhong Huang

Fujian Normal University

Baixue Lin

Institute of Microbiology Chinese Academy of Sciences\&University of Chinese Academy of Sciences

Yong Tao

Institute of Microbiology Chinese Academy of Sciences\&University of Chinese Academy of Sciences

\section{Research}

Keywords: AQ, Metabolic engineering, Whole-cell biocatalysis, L-amino acid a-ligase, Glutamine synthase

Posted Date: March 31st, 2020

DOI: https://doi.org/10.21203/rs.2.18175/v2

License: (1) This work is licensed under a Creative Commons Attribution 4.0 International License. Read Full License

Version of Record: A version of this preprint was published at Microbial Cell Factories on June 11th, 2020. See the published version at https://doi.org/10.1186/s12934-020-01369-2. 


\section{Abstract}

Background L-alanyl-L-glutamine (AQ) is a functional dipeptide with high water solubility, good thermal stability and high bioavailability. It is widely used in clinical medicine, post-operative rehabilitation, sports health care and other fields. AQ is mainly produced by chemical synthesis which is complicated, time-consuming, labor-consuming, low yield and accompany with by-products. It is highly desirable to develop an efficient biotechnological process for AQ production.

Results A metabolic engineered E. coli strain for AQ production was developed by over-expressing L-amino acid-ligase (BacD) from Bacillus subtilis , peptidases including PepA, PepB, PepD, PepN and dipeptide transport system Dpp were inactivated. In order to use the more readily available substrate, glutamic acid, a glutamine synthetic module from glutamic acid to glutamine was constructed by introducing glutamine synthetase (GlnA), glsA-glsB catalyze the first step in glutamine metabolism and glnE-glnB involved in the ATP-dependent addition of AMP/UMP to a subunit of glutamine synthetase were blocked which resulted in increased glutamine supply. This glutamine synthetic module combined with $A Q$ synthetic module to develope the engineered strain that using glutamic acid and alanine for $A Q$ production. The expression of BacD and GInA was further balanced to improve the AQ production. The engineered strain p15/AQ10 was used in the whole-cell biocatalysis and $65.6 \mathrm{mM} \mathrm{AQ}$ was produced with productivity of $7.29 \mathrm{mM} / \mathrm{h}$ and conversion rate of $65.6 \%$.

Conclusion Metabolic engineered strains were developed for AQ production. Strategies including inactivation of peptidases, screening of $B a c D$, introducing glutamine synthetic module, and balancing the glutamine and AQ synthetic modules were applied to improve the yield of AQ. This work provides the biosynthetically industrial potential for efficient production of AQ by microbial cell factory.

\section{Background}

Glutamine (L-GIn) plays an important role in maintaining intestinal function[1-4], promoting immune function[5, 6], maintaining homeostasis of the internal environment[7] and improving the adaptability of organism to stress[8]. During disease or stress conditions, demand outpaces supply, and glutamine becomes conditionally essential[9]. The supply of exogenous L-glutamine or glutamyl dipeptide is an important nutritional solution to reduce glutamine deficiency in vivo, and it used to be applied in clinical treatment. However, some characteristics of glutamine such as low solubility in water, easy decomposition and poor thermal stability, as well as production of toxic pyroglutamate during heat sterilization restricted its application in medicine. Otherwise, as a result of its unstable nature, the low yield of glutamine during the purification process is a great challenge [10].

L-alanyl-L-glutamine (abbreviated as AQ) is a dipeptide of glutamine and alanine, which is more stable and water-soluble than glutamine. $\mathrm{AQ}$ is hydrolyzed to release glutamine and alanine in vivo. While it acts as a source of glutamine, $A Q$ has higher bioavailability and a short half-life[11], and cannot cause cumulative damage to the body, so it is used as a substitute for glutamine in clinical practice.

The commercial demand for AQ is increasing with the expansion of new applications and the development of new products based on AQ. Chemical and biotechnological methods for AQ production have been developed[12-16]. AQ can be synthesized by chemical condensation of benzyloxycarbonyl-L-alamine and methyl glutamate via activated ester[17] or triphenyl phosphine/hexachloroethane condensation, which used to require complex steps such as amino acid activation, subunit protection, and removing the protective groups. Enzymatic processes for $A Q$ production have been developed using an a-amino acid ester acyltransferase $[18,19]$. Tabata and Hashimoto engineered Escherichia coli by expressing L-amino acid a-ligase (BacD), which catalyzes the formation of AQ in an ATP-dependent manner, and produced more than $100 \mathrm{mM} \mathrm{AQ}$ in 47h of fermentation [20]. Whole-cell biocatalysis can be used to realize enzyme cascade reaction, improve catalytic efficiency, and simplify the preparation process.

A metabolically engineered $E$. coli strain for AQ production was developed by over-expressing L-amino acid a-ligase (BacD) from Bacillus subtilis and inactivating native peptidases. In order to use a more readily available substrate, the glutamine synthesis module based on introducing glutamine synthetase ( $(\mathrm{In} A)$ was constructed and optimized. Then glutamine synthesis module was combined with the AQ synthesis module to use glutamic acid and alanine for $A Q$ production. The protein expression of $B a c D$ and GInA was further balanced to improve the $A Q$ production. Finally, we used the engineered strain to develop a whole-cell biocatalytic process for AQ production (Fig. 1). This work provides an environmentally friendly, highly efficient and cost-effective process for industrial biosynthesis of AQ.

\section{Results}

\section{Construction of the AQ Synthesis Module}

The E.coli strain p01/BW25113, overexpressing BacD from Bacillus subtilis (BsBacD) which catalyzes the formation of AQ from alanine and glutamine, was constructed for the production of AQ. Extracellular AQ concentration was measured by HPLC, and $2.0 \mathrm{mM}$ AQ was 
obtained (Fig. 2).

In E. coli, peptidases encoded by $\operatorname{pepA,~} \operatorname{pepB}$, $\operatorname{pep} D$ and $p e p N$, have been reported to degrade a broad spectrum of dipeptides[20, 21], and inactivating them might reduce $\mathrm{AQ}$ degradation. It was reported that deletion of $d p p$, encoding a dipeptide $\mathrm{ABC}$ transporter increased $\mathrm{AQ}$ accumulation [20, 22, 39]. By knocking out the genes $\operatorname{pep} N$, pepA, pepB, pepD and $d p p$, the degradation of $A Q$ was alleviated. In the starting host BW25113, $20 \mathrm{mM}$ AQ was completely degraded after 3 hours, compared to only $1.3 \mathrm{mM}$ in the chassis AQ09 (BW25113 $\Delta p e p N$, $\triangle p e p A, \triangle p e p B, \triangle p e p D, \triangle d p p$ ) after 6 hours. A whole-cell biocatalysis system with the strain (p01/AQ09) yielded $3.3 \mathrm{mM} \mathrm{AQ}$ after $18 \mathrm{~h}$ (Fig. 2). These results demonstrated that inactivation of peptidases and the dipeptide transporter Dpp reduced the degradation of $A Q$, and thus increased $A Q$ production.

\section{Screening of BacD homologues}

$B a c D$ is the key enzyme for $A Q$ synthesis. We examined the known sequences annotated as L-amino acid a-ligase (BacD) in the NCBI database. According to the sequences of known or predicted $\mathrm{BaCD}$ homologs, we selected a set of related sequences from different species, and constructed a phylogenetic tree of the previously reported BacD homologs and those used in this study (Fig. S1). The genes encoding BacD homologs from different species were codon-optimized by Nanjing Generay (China) and cloned into strain AQ10 ( $B W 25113, \Delta g I n E B, \Delta g / s A B, \Delta / p x M, \triangle p e p A B D N, \Delta d p p$ ). The performance of different BacD proteins was investigated in vivo, using the respective strains as a whole-cell biocatalysts. The result showed that the strain overexpressing $B a B a c D$ (from Bacillus altitudinis) produced higher amount of $A Q(19.2 \mathrm{mM})$ than strains with other BacD homologs. By comparison, $7.9 \mathrm{mM} A Q$ was obtained using the strain overexpressing BsBacD (from Bacillus subtilis) (Fig. 3). Although there was soluble expression of BvBacD (from Beta vulgaris), VcBacD (from Vibrio campbellii), and SrBacD (from Streptomyces rubrolavendulae), only 3.0, 1.8, $0.5 \mathrm{mM}$ AQ was respectively obtained(Fig. 3). BsaBacD (from Bacillus safensis), BloBacD (from Bifidobacterium longum subsp. infantis), PmBacD (from Perkinsus marinus), and PfBacD (from Pseudomonas fluorescens) were expressed as inclusion bodies (Fig. S2), and only a low amount of AQ was detected.

\section{Construction of a glutamine synthesis module}

To use the more readily available substrate glutamic acid, glutamine synthetase from Corynebacterium glutamicum (CgGlnA), which convert glutamic acid to glutamine was cloned into $E$. coli, resulting in the strain p00/BW25113. A final glutamine titer of $22.4 \mathrm{mM}$ glutamine was obtained in the whole-cell bioconversion. During growth nitrogen replete growth conditions, glutamine synthetase adenyly|transferase/deadenylase (encoded by $g \ln E$ ) interacts with PII-1 protein encoded by $g / n B$, which reduces the activity of glutamine synthetase, and $g / n E$-glnB-deficiency was reported to lead to increased glutamine accumulation [23-25]. Therefore, a $g / n E$-glnB-deficient strain expressing $g \ln A$ (p00/AQ02) was constructed, and a glutamine titer of $27.8 \mathrm{mM}$ was achieved, which was $24.1 \%$ higher than that of the strain p00/BW25113 (Fig. 4). In E. coli, glutamine was converts into glutamic acid by glutaminases GlsA (encoded by g/sA) and GlsB (encoded by $g / s B$ )[26], and further into a-ketoglutarate. Consequently, the $g / s A$ and $g / s B$ genes were deleted, resulting in strain AQ04 $(\Delta g / s A \Delta g / s B)$, which was then transformed with the plasmid p00, and the resulting strain p00/AQ04 produced $33.8 \mathrm{mM}$ of glutamine after 18 hours of bioconversion. Further, $g / n E, g / n B, g / s A, g / s B$ and $I p x M$ were sequentially knocked out and $46.5 \mathrm{mM}$ glutamine was accumulated by the resulting strain p00/AQ06, with a conversion rate of $93.0 \%$ (Fig. 4). Consequently, the strain p00/AQ06 was used for further engineering.

\section{Combination the $\mathrm{AQ}$ and glutamine synthesis modules}

To achieve $A Q$ production from glutamic acid and alanine, the $A Q$ and glutamine synthesis modules were combined. The strain $A Q 10$ was obtained by knocking out the genes $p e p N$, pepA, pepB, pepD, dpp, glnE, glnB, glsA, glsB and IpxM. In AQ10, the degradation of AQ was alleviated, glutamine catabolism was effectively weakened as well. After introducing BsBacD, the resulting strain p01/AQ10 produced 7.9 $\mathrm{mM} \mathrm{AQ}$, which was four times more than the production of the original strain p01/BW25113 (Fig. 2).

The engineered strains with the plasmid p11 (pYB1s-CgglnA-BsbacD), co-expressing BsBacD and CgGlnA was used as a whole-cell biocatalyst for $\mathrm{AQ}$ production from alanine and glutamic acid. Removal of the peptidases PepA, PepB, PepD, and PepN, together with knocking out the transporter Dpp significantly increased AQ production, and a titer of $17.9 \mathrm{mM}$ was produced by the strain AQ09 harboring p11 (Fig. 5). Due to the downregulation of $g / n E-g / n B$ and $g / s A g / s B$, the biosynthesis of glutamine was enhanced, which resulted in increased AQ production, leading to a product titer of $29.8 \mathrm{mM}$ in the strain AQ10 harboring p11 (Fig. 5). Inactivation of peptidases alleviated $\mathrm{AQ}$ degradation, and removing the transporter Dpp promoted the efflux of $\mathrm{AQ}$. The results showed that combination of the strategies of peptidases inactivation, knocking out the transporter Dpp, and enhancing the glutamine supply by downregulation of $g / n E-$ $g / n B$ and $g / s A-g / s B$ greatly enhanced AQ production. 
To balance flux in the two synthesis module for the purpose of increasing $A Q$ production, the expression of BacD and GInA proteins was studied. To co-express BaBacD or BsBacD with CgGlnA in different order, four plasmids p11 (pYB1s-CgglnA-BsbacD), p12 (pYB1s-BsbacDCgglnA), p13 (pYB1s-CgglnA-BabacD), and p14 (pYB1s-BabacD-CgglnA) were constructed (Fig. 6c), and used to individually transform the host AQ10. Either L-amino acid a-ligase or glutamine synthetase was poorly expressed when BaBacD was co-expressed with CgGlnA (Fig. S3), leading to decreased AQ production. However, when CgGlnA was co-expressed with BsBacD, both proteins were expressed at high levels, and contributed to an increased yield of $A Q$ after $18 \mathrm{~h}$ of bioconversion. The AQ titer reached $29.8 \mathrm{mM}$ when $\mathrm{Cgg} / \mathrm{n} A$ was inserted in front of $B s b a c D$ (p11/AQ10), compared to $22.3 \mathrm{mM}$ when $C g g / n A$ was expressed behind BsbacD (p12/AQ10) (Fig. 6a). The concentration of the intermediate metabolite, glutamine, in p11/AQ10 (22.8 mM) was higher than in p12/AQ10 (12.0 mM) (Fig. 6a). SDS-PAGE analysis of protein expression (Fig. S3) and the concentration of glutamine suggested that higher soluble expression of $\mathrm{CgGlnA}$ enhanced the supply of glutamine, and increasing the expression of BsBacD might further improve the synthesis of AQ.

In order to enhance the expression of BsBacD, its native RBS was replaced to upregulate the mRNA translation initiation rate in the recombinant strain. The translation rate prediction and design of new RBS was done using RBS Calculator 2.0[27-29]. The strain p15/AQ10 expressed more BsBacD protein (Fig. S4), and its AQ production increased by $76.1 \%$ compared to p11/AQ10 (Fig. 6b).

\section{Optimization of the conditions for whole-cell biocatalysis}

After successfully constructing an engineered E.colistrains for AQ production by metabolic engineering, we investigated its applicability as whole-cell biocatalyst for the biotechnological production of AQ. Bioconversion parameters that affect the activity of the biocatalyst, such as temperature and $\mathrm{pH}$, were investigated. $\mathrm{AQ}$ production reached maximal values at $30^{\circ} \mathrm{C}$ (Fig. $7 \mathrm{a}$ ) and pH 9.0 (Fig. $7 \mathrm{~b}$ ). A decreased in pH was observed as the bioconversion proceeded, which affected the biosynthesis of AQ. It should be noted that glucose was supplemented in the reaction mixture to supply ATP for the reactions catalyzed by $G \ln A$ and $B a c D$, it was reported that excess glucose can lead to acetate accumulation. Consequently, we measured the concentration of acetate and found that it was accumulated. To alleviate this, different glucose feeding strategies were applied to reduce acetate accumulation in the bioconversion process, including 1) $50 \mathrm{mM}$ glucose at once; 2) $10 \mathrm{mM}$ every 3 hours; and 3) $20 \mathrm{mM}$ every 3 hours. When a low concentration of glucose (10 mM) was fed every three hours (Fig. 7c), glucose was fully utilized (Fig. S5a), and only a small amount of acetic acid accumulated (Fig. S5b ), indicating that $10 \mathrm{mM}$ glucose fed every three hours matched AQ productivity. The time profiles of the bioconversion indicated that alanine was exhausted first, and the ratio of glutamic acid to alanine was investigated (Fig.7d). Under feeding with $10 \mathrm{mM}$ glucose every three hours at $30{ }^{\circ} \mathrm{C}$ and $\mathrm{pH} 9.0$, the strain p15/AQ10 produced $71.7 \mathrm{mM} \mathrm{AQ}$, from $100 \mathrm{mM}$ glutamic acid and $125 \mathrm{mM}$ alanine, after 18 hours of reaction, corresponding to a productivity of $3.98 \mathrm{mM} / \mathrm{h}$. Moreover, a conversion rate of $71.7 \%$ was achieved for glutamic acid representing a $100 \%$ increase compared to the conversion rate before the optimization.

\section{Discussion}

In this study, we constructed a metabolically engineered E. coli strain for AQ production by overexpressing L-amino acid $\alpha$-ligase from Bacillus subtilis, knocking out peptidases PepA, PepB, PepD, and PepN, as well as the transporter Dpp, which effectively weakened AQ degradation. To use a more readily available and cheaper substrate, a module for the synthesis of glutamine from glutamic acid was constructed by overexpressing glutamine synthetase from Corynebacterium glutamicum. It was reported that the glutaminases GlsA-GlsB convert glutamine to glutamic acid, which is the main pathway of glutamine catabolism, while GlnE interacts with GlnB to induce the deadenylation/deuridylylation of glutamine synthetase under nitrogen-rich growth, leading to a reduction of the activity of glutamine synthetase. Thus, GlsA, GlsB, GlnE, and GlnB were blocked, which resulted in increased glutamine supply with a $93.0 \%$ bioconversion of glutamic acid. Then AQ and glutamine synthesis modules were coupled, and 29.8 mM AQ production was achieved by co-expressing BsBacD and CgGlnA. To balance the flux through two modules, the expression of BacD and GlnA was fine-tuned by modifying the RBS, and AQ production was further increased by 76.1\%. Finally, the reaction conditions for the whole-cell biocatalysis were optimized, and $71.7 \mathrm{mM} \mathrm{AQ}$ was obtained using strain p15/AQ10 after 18 hours of reaction, with productivity of $3.98 \mathrm{mM} / \mathrm{h}$ and a conversion rate of $71.7 \%$ from glutamic acid to AQ was achieved.

Both fermentation and enzymatic processes for AQ production were reported. We compared the AQ biosynthesis results obtained in this study with previous studies, as shown in Table. 1. Enzymatic processes were reported for AQ production from L-alanine methyl ester hydrochloride (AlaOMe) 
and glutamine using amino acid ester acyltransferase[18, 32, 33]. The substrates used in the process, AlaOMe and glutamine are expensive, making the process not economically feasible. Tabata and Hashimoto reported a fermentative process for AQ production from glucose using a engineered E.coli strain co-expressing L-amino acid $\alpha$-ligase (Lal) and L-alanine dehydrogenase (Ald) in the strain background of JKYPQ3 ( $p e p A$ pepB $p e p D$ pepN $d p p$ glnE glnB putA) [20]. The amino acids needed for AQ production were biosynthesized from glucose. However, it was challenging to balance the ratio of glutamine and alanine, which might affect AQ production. Moreover, the synthesis of amino acids is generally tightly regulated. Therefore, AQ accumulation was slow, and the productivity of AQ was low in the fermentation process. In this study, AQ was synthesized from glutamic acid and alanine using whole-cell biocatalytic process. Alanine was added to the reaction mixture as substrate, and glutamine was synthesized from externally added glutamic acid. A very small amount of glucose was used to supply ATP. The concentrations of the substrates (glutamate and alanine) can be easily controlled. The productivity of AQ in this study was $3.98 \mathrm{mM} / \mathrm{h}$ which was much higher than previously reported [20].

Table. 1 Production of AQ using engineered E.coli

\begin{tabular}{|c|c|c|c|c|c|}
\hline Strain & Deletion of gene & $\begin{array}{l}\text { Overexpression } \\
\text { of genes }\end{array}$ & Process & AQ & References \\
\hline $\begin{array}{l}\text { E.coli } \\
\text { JKYPQ3/pPE167 }\end{array}$ & $\Delta p e p A \Delta p e p B \Delta p e p D \Delta p e p N \Delta d p p \Delta p r o \Delta g \ln B \Delta g \ln E \Delta p u t A$ & $\begin{array}{l}\text { L-amino acid } \alpha \text { - } \\
\text { ligase } \\
\text { (Lal/BacD) and } \\
\text { L-alanine } \\
\text { dehydrogenase } \\
\text { (Ald) }\end{array}$ & $\begin{array}{l}\text { Fermentation } \\
\text { from glucose }\end{array}$ & $\begin{array}{l}7.4 \mathrm{mM} \text { in } \\
\text { test tube } \\
\text { in } 47 \mathrm{~h} \\
100 \mathrm{mM} \\
(24.7 \mathrm{~g} / \mathrm{L}) \\
\text { in } \\
\text { fermenter } \\
\text { in } 47 \mathrm{~h}\end{array}$ & [20] \\
\hline $\begin{array}{l}\text { E. brevis ATCC } \\
14234\end{array}$ & None & $\begin{array}{l}\alpha \text {-amino acid } \\
\text { ester } \\
\text { acyltransferase }\end{array}$ & $\begin{array}{l}\text { Enzymatic } \\
\text { production by } \\
\text { purified } \\
\text { enzyme from } \\
\text { AlaOMe and } \\
\text { Gln }\end{array}$ & $\begin{array}{l}83 \mathrm{mM} \\
(18.0 \mathrm{~g} / \mathrm{L}) \\
\text { in } 1 \mathrm{~h}\end{array}$ & [32] \\
\hline $\begin{array}{l}\text { E.coli SP1 } \\
\text { /pSaet }\end{array}$ & $\Delta p e p D$ & $\begin{array}{l}\alpha \text {-amino acid } \\
\text { ester } \\
\text { acyltransferase }\end{array}$ & $\begin{array}{l}\text { Enzymatic } \\
\text { production } \\
\text { from AlaOMe } \\
\text { and Gln }\end{array}$ & $\begin{array}{l}320 \mathrm{mM} \\
(69.7 \mathrm{~g} / \mathrm{L}) \\
\text { in } 40 \mathrm{~min}\end{array}$ & [33] \\
\hline $\begin{array}{l}\text { E.coli } \\
\text { OPA }\end{array}$ & None & $\begin{array}{l}\alpha \text {-amino acid } \\
\text { ester } \\
\text { acyltransferase }\end{array}$ & $\begin{array}{l}\text { Enzymatic } \\
\text { production } \\
\text { from AlaOMe } \\
\text { and Gln }\end{array}$ & $\begin{array}{l}367.9 \mathrm{mM} \\
(79.8 \mathrm{~g} / \mathrm{L}) \\
\text { in } 20 \mathrm{~min}\end{array}$ & [18] \\
\hline E.coli $p 15 / A Q 10$ & $\Delta g l s A \Delta g l s B \Delta \operatorname{lp} x M \Delta g \ln B \Delta g \ln E \Delta p e p A \Delta p e p B \Delta p e p D \Delta p e p N \Delta d p p$ & $\begin{array}{l}\text { L-amino acid } \alpha \text { - } \\
\text { ligase } \\
\text { (Lal/BacD) and } \\
\text { glutamine } \\
\text { synthetase } \\
\text { (GlnA) }\end{array}$ & $\begin{array}{l}\text { whole-cell } \\
\text { biocatalytic } \\
\text { conversion of } \\
\text { glutamic acid } \\
\text { and alanine }\end{array}$ & $\begin{array}{c}71.7 \mathrm{mM} \\
(14.2 \mathrm{~g} / \mathrm{L}) \\
\text { in test } \\
\text { tube in } \\
18 \mathrm{~h}\end{array}$ & This study \\
\hline
\end{tabular}

It was reported that expression of L-amino acid $\alpha$-ligase exerted a negative effect on cell growth in the fermentation[20].In the whole-cell bioconversion, cell growth (the enzyme manufacturing phase) and the AQ production phase were separated. Substrates were converted to AQ by resting cells in the production phase. Therefore, the growth inhibitory effect of L-amino acid $\alpha$-ligase was reduced.

BacD enzymes have been reported to have insufficient substrate specificity and form by-products, such as different dipeptides or longer oligopeptides[30], which undoubtedly increases the cost of downstream separation and purification of target products. In this study, the extracellular concentrations of Ala-Ala reached $12.4 \mathrm{mM}$ after $18 \mathrm{~h}$ of reaction, and no other dipeptides or longer oligopeptides were detected. The concentration of alanine decreased faster than that of glutamic acid, which suggested that the conversion of alanine should be reduced. Further studies are 
underway to improve the system including screening of BacD homologs with higher enzymatic activity and substrate specificity, enhancing AQ efflux using dipeptide efflux pump, reducing the degradation of alanine by blocking its catabolism, and scale-up of the bioconversion in fermenters.

\section{Conclusions}

In this study, we conducted systematic metabolic engineering of E.coli to develop a whole-cell biocatalysis for the synthesis of AQ from glutamic acid and alanine. Inactivation of peptidases and the dipeptide transport system, combined with screening of BacD homologs improved the yield of $\mathrm{AQ}$. The supply of glutamine from glutamic acid was improved by overexpression of glutamine synthetase (GInA), reduction of glutamine degradation by inactivating of glutaminases $(\Delta g / s A \Delta g / s B)$, and deregulation of glutamine biosynthesis $(\Delta g \ln E \Delta g \ln B)$. The final engineered E.coli strain p15/AQ10 produced $71.7 \mathrm{mM}$ AQ with a conversion rate of $71.7 \%$ for glutamic acid. This study offers the new opportunities for the bio-industrial production of AQ. The metabolic engineering strategies developed in this study can be applied in the synthesis of other high-value-added dipeptides and oligopeptides.

\section{Materials And Methods}

\section{Construction of plasmids and strains}

Escherichia coli K12 (BW25113) was used for protein expression. All bacteria strains and plasmids used in this study are listed in Table. 2. Target genes (CgglnA, BsbacD, BabacD, BlabacD, BvbacD, VcbacD, BlabacD, PfbacD, BlobacD, PmbacD, BsabacD, and SrbacD) were codon-optimized and synthesized by Generay (Shanghai, China), and then ligated into pYB1a between the Xho I and EcoR I sites via Gibson assembly[34]. Inactivation of genes was conducted using the CRISPR-Cas9 system[35].

Table. 2 Strains and plasmids used in this study

\begin{tabular}{|c|c|c|}
\hline Strains/plasmids & Characteristics & Source \\
\hline \multicolumn{3}{|l|}{ Strains } \\
\hline E.coli BW25113 & IacI $^{q} r r n B_{T 14} \Delta l a c Z_{W J 16} h s d R 514 \Delta a r a B A D_{A H 33} \Delta r h a B A D_{L D 78}$ & Invitrogen \\
\hline AQ02 & E. coli BW25113, $\Delta g \ln E, \Delta g \ln B$ & This study \\
\hline AQ04 & E. coli BW25113, $\Delta$ gls $A, \Delta$ glsB & This study \\
\hline AQ06 & E. coli BW25113, $\Delta g \ln E, \Delta g \ln B, \Delta g l s A, \Delta g l s B, \Delta \operatorname{lpx} M$ & This study \\
\hline AQ09 & E. coli BW25113, $\Delta$ pepA, $\Delta$ pepB, $\Delta$ pepD, $\Delta$ pepN, $\Delta d p p$ & This study \\
\hline AQ10 & E. coli $B W 25113, \Delta g \ln E, \Delta g \ln B, \Delta g \operatorname{ls} A, \Delta g l s B, \Delta \operatorname{lpx} M, \Delta p e p A, \Delta p e p B, \Delta p e p D, \Delta p e p N, \Delta d p p$ & This study \\
\hline $\mathrm{p} 11 / \mathrm{AQ} 10$ & AQ10 expressing p11 & This study \\
\hline $\mathrm{p} 12 / \mathrm{AQ} 10$ & AQ10 expressing p12 & This study \\
\hline p13/AQ10 & AQ10 expressing p13 & This study \\
\hline p14/AQ10 & AQ10 expressing p14 & This study \\
\hline p15/AQ10 & AQ10 expressing p15 & This study \\
\hline $\mathrm{p} 16 / \mathrm{AQ} 10$ & AQ10 expressing p16 & This study \\
\hline \multicolumn{3}{|l|}{ Plasmids } \\
\hline pYB1a & P15A origin, $\mathrm{pBAD}$ promoter, $\mathrm{Amp}^{\mathrm{R}}$ & Our lab \\
\hline pYB1s & P15A origin, pBAD promoter, $\mathrm{Str}^{\mathrm{R}}$ & Our lab \\
\hline p00 & glnA from Corynebacterium glutamicum cloned into pYB1a & This study \\
\hline p01 & bacD from Bacillus subtilis cloned into pYB1a & This study \\
\hline p02 & bacD from Bacillus altitudinis cloned into pYB1a & This study \\
\hline p03 & bacD from Beta vulgaris cloned into pYB1a & This study \\
\hline p04 & bacD from Vibrio campbellii cloned into pYB1a & This study \\
\hline p05 & bacD from Streptomyces rubrolavendulae cloned into pYB1a & This study \\
\hline p06 & bacD from Bacillus safensis cloned into pYB1a & This study \\
\hline p07 & bacD from Bifidobacterium longum subsp. Infantis cloned into pYB1a & This study \\
\hline p08 & bacD from Brevibacillus laterosporus cloned into pYB1a & This study \\
\hline p09 & bacD from Perkinsus marinus cloned into pYB1a & This study \\
\hline p10 & bacD from Pseudomonas fluorescens cloned into pYB1a & This study \\
\hline p11 & $C g g \ln A-B s b a c D$ cloned into pYB1s & This study \\
\hline p12 & BsbacD-CgglnA cloned into pYB1s & This study \\
\hline p13 & $C g g \ln A-B a b a c D$ cloned into pYB1s & This study \\
\hline p14 & BabacD-CgglnA cloned into pYB1s & This study \\
\hline p15 & BsbacD mRNA corresponding translation initiation rate was predicted to be 176300 & This study \\
\hline p16 & BsbacD mRNA corresponding translation initiation rate was predicted to be 295800 & This study \\
\hline
\end{tabular}




\section{Culture condition}

Strains were grown in LB medium (10 g/L tryptone, $5 \mathrm{~g} / \mathrm{L}$ yeast extract, $10 \mathrm{~g} / \mathrm{L} \mathrm{NaCl})$ at $37^{\circ} \mathrm{C}$ and $220 \mathrm{rpm}$. Antibiotics (ampicillin $100 \mathrm{\mu g} / \mathrm{mL}$, or streptomycin $40 \mathrm{\mu g} / \mathrm{mL}$ ) were added as required. For protein expression, auto-inducing ZYM medium (per liter: tryptone $10 \mathrm{~g}$, yeast extract $5 \mathrm{~g}$, glycerol $5 \mathrm{~g}$, glucose $0.5 \mathrm{~g}$, L-arabinose $2 \mathrm{~g}, \mathrm{Na}_{2} \mathrm{HPO}_{4} 25 \mathrm{mM}, \mathrm{KH}_{2} \mathrm{PO}_{4} 25 \mathrm{mM}, \mathrm{NH}_{4} \mathrm{Cl} 50 \mathrm{mM}, \mathrm{Na}_{2} \mathrm{SO}_{4} 5 \mathrm{mM}, \mathrm{MgSO}_{4} 2$ mM, and trace elements including $0.05 \mathrm{mM} \mathrm{FeCl}_{3}, 0.02 \mathrm{mM} \mathrm{CaCl}_{2}, 0.01 \mathrm{mM} \mathrm{MnCl}_{2}, 0.01 \mathrm{mM} \mathrm{ZnSO}_{4}$, and $0.002 \mathrm{mM}$ each of $\mathrm{CoCl}_{2}, \mathrm{NiCl}_{2}, \mathrm{Na}_{2} \mathrm{Mo}_{4}, \mathrm{Na}_{2} \mathrm{SeO}_{3}$, and $\left.\mathrm{H}_{3} \mathrm{BO}_{3}\right)$ was used[36], and the strains were allowed to auto-induced at $30{ }^{\circ} \mathrm{C}$ for $12-16 \mathrm{~h}$.

\section{Whole-cell biocatalysis conditions}

Cells were harvested after induction by centrifugation at $5000 \times \mathrm{g}$ for $10 \mathrm{~min}$, washed once with $0.85 \% \mathrm{NaCl}$ solution, and then used for the production of AQ via whole-cell biocatalytic conversion[37]. For AQ synthesis from glutamine and alanine, the conversion system contained $50 \mathrm{mM}$ MOPS (morpholine propane sulfonic acid) buffer pH7.0, $50 \mathrm{mM}$ glutamine, $50 \mathrm{mM}$ alanine, $10 \mathrm{mM}$ magnesium chloride, and $50 \mathrm{mM}$ glucose with a starting $\mathrm{OD}_{600 \mathrm{~nm}}=30$. The bioconversion reaction was performed at $30^{\circ} \mathrm{C}$ and $220 \mathrm{rpm}$ in a test tube. Glucose was supplemented at a concentration of $10 \mathrm{mM}$ every three hours. For glutamine synthesis, the cells were suspended in $1 \mathrm{~mL}$ bioconversion medium containing $50 \mathrm{mM}$ MOPS buffer pH7.0, $50 \mathrm{mM}$ sodium glutamate, $100 \mathrm{mM}$ ammonium chloride, $10 \mathrm{mM}$ magnesium chloride, $50 \mathrm{mM}$ glucose to form a cell suspension with a starting $\mathrm{OD}_{600 \mathrm{~nm}}=30$. For $\mathrm{AQ}$ production from glutamic acid and alanine, the conversion system contained $50 \mathrm{mM}$ MOPS buffer pH9.0, $100 \mathrm{mM}$ sodium glutamate, $100 \mathrm{mM}$ alanine, $100 \mathrm{mM}$ ammonium chloride, $10 \mathrm{mM}$ magnesium chloride, and $50 \mathrm{mM}$ glucose.

In the process of optimizing the whole-cell catalytic conditions, the bioconversion reaction was performed at different temperatures (20-45 $\left.{ }^{\circ} \mathrm{C}\right)$ and $\mathrm{pH}$ values (6.0-11.0). When optimizing the strategy of glucose feeding, three different strategies were investigated: 1) $50 \mathrm{mM}$ glucose at one time; 2) 10mM glucose was added every 3 hours; and 3) $20 \mathrm{mM}$ glucose was added every 3 hours. When the concentration of substrate was studied, 100 to $200 \mathrm{mM}$ alanine was added at once, together with $100 \mathrm{mM}$ sodium glutamate.

\section{Analytical methods}

Biomass was estimated by measuring the optical density at $600 \mathrm{~nm}$. Proteins expression was analyzed by SDS-PAGE. The concentrations of glucose and acetate in the supernatant were determined by HPLC on a Bio-Rad Aminex HPX-87H Ion Exclusion column (7.8×300 mm; Hercules, CA, USA), with a refractive index detector. Analysis was performed at $55^{\circ} \mathrm{C}$ with a mobile phase of $5 \mathrm{mM} \mathrm{H}_{2} \mathrm{SO}_{4}$ at a flow rate of $0.5 \mathrm{~mL} / \mathrm{min}$.

The AQ and amino acids including glutamine, glutamic acid, and alanine, were derivatized using 9-fluorenylmethoxy carbonyl chloroformate and measured by HPLC as described by Kazuhiko Tabata [38] , with minor modifications as follows. The mobile phase components A and B were acetonitrile and $50 \mathrm{mM}$ sodium acetate, and the gradient program was slightly modified as follows: 0 min, solvent A-solvent B at 10 : 90 ; 0 to 20 min, a linear increase in solvent A to A-B at 60: 40; 20 to 24 min, a linear increase to A-B at 100: 0; 24 to 27 min, held at A-B at 100:0; 27 to 28 min, a linear decrease in solvent B to A-B at 10: 90 . The column temperature was set at $30^{\circ} \mathrm{C}$, the injection volume was $5 \mu \mathrm{L}$, and the flow rate was 0.6 $\mathrm{mL} / \mathrm{min}$.

\section{Declarations}

\section{Acknowledgements}

This work was supported by the National Natural Science Foundation of China Grant (31670051) and the National Key Research and Development Program of China (2018YFA0901400).

\section{Additional file}


Additional file : Fig. S1. Phylogenetic tree of BacD homologs. Fig. S2. SDS-PAGE analysis of different BacD proteins in E.coli. Fig. S3. SDSPAGE analysis of strains which co-expressing CgGInA and BacD. Fig. S4. SDS-PAGE analysis of strains by RBS optimization. Fig. S5 Concentration of glucose and acetic acid in the conversion.

\section{Abbreviations}

AQ, L-alanyl-L-glutamine; GInA, glutamine synthetase; BacD, L-Amino Acid a-Ligase;

SDS-PAGE, Sodium dodecyl sulfate-polyacrylamide gel electrophoresis; HPLC, high-performance liquid chromatography.

\section{Authors' contributions}

J-M Z carried out the main work, collected and analyzed the data, and drafted the manuscript. WY, B-H W, QL, X-T Z, Q-X G, J-Z L participated in the research. B-XL supervised the work, design of the study, participated in data analysis, and revised the manuscript. J-Z $\mathrm{H}$ and $Y$ T participated in the conception and finalized the manuscript. All authors read and approved the final manuscript.

\section{Author details}

Chinese Academy of Sciences Key Laboratory of Microbial Physiological and Metabolic Engineering, Institute of Microbiology, Chinese Academy of Sciences, Beijing 100101, China.

\section{Competing interests}

The authors declare that they have no competing interests.

\section{Availability of data and materials}

All data generated or analyzed during this study are included in this published article and its additional file.

\section{Consent for publication}

Not applicable.

\section{Ethics approval and consent to participate}

Not applicable.

\section{Funding}

National Natural Science Foundation of China Grant (31670051) and the National Key Research and Development Program of China (2018YFA0901400).

\section{References}

1. Stehle P, Kuhn KS: Glutamine: an obligatory parenteral nutrition substrate in critical care therapy. Biomed Res Int 2015, $2015: 545467$.

2. Labow BI, Souba WW: Glutamine. World Journal of Surgery 2014, 24:1503-1513.

3. Fuentes-Orozco C, Anaya-Prado R, González-Ojeda A, Arenas-Márquez H, Cabrera-Pivaral C, Cervantes-Guevara G, Barrera-Zepeda LM: I-Alanyl-I-glutamine-supplemented parenteral nutrition improves infectious morbidity in secondary peritonitis. Clinical Nutrition 2004 , 23:13-21.

4. Lasierra JLF, Carmona TG: I-Alanyl-I-glutamine dipeptide-supplemented total parenteral nutrition. In Diet and Nutrition in Critical Care 2014 2014: 1-11.

5. Moore SR, Guedes MM, Costa TB, Vallance J, Maier EA, Betz KJ, Aihara E, Mahe MM, Lima AA, Oria RB, Shroyer NF: Glutamine and alanyl-glutamine promote crypt expansion and mTOR signaling in murine enteroids. Am J Physiol Gastrointest Liver Physiol 2015, 308:G831-839.

6. Mundi MS, Shah M, Hurt RT: When is it appropriate to use glutamine in critical illness? Nutr Clin Pract 2016, 31:445-450.

7. R R W J van der Hulst, Meyenfeldt M F V, Soeters P B: Glutamine: a gut essential amino acid. 
8. Zhou Y, Zhang P, Deng G, Liu X, Lu D: Improvements of immune status, intestinal integrity and gain performance in the early-weaned calves parenterally supplemented with L-alanyl-L-glutamine dipeptide. Vet Immunol Immunopatho/ 2012, 145:134-142.

9. Furst P, Pogan K, Stehle P: Glutamine dipeptides in clinical nutrition. Nutrition 1997, 13(7-8): 731-737.

10. Li S L, Li C, Liu Y S, Wang X L, Cao Z A: Separation of (l)-glutamine from fermentation broth by nanofiltration. Journal of Membrane Science 2003, 222(1-2): 191-201.

11. Tan B, Liu H, He G, Xiao H, Xiao D, Liu Y, Wu J, Fang J, Yin Y: Alanyl-glutamine but not glycyl-glutamine improved the proliferation of enterocytes as glutamine substitution in vitro. Amino Acids 2017, 49:2023-2031.

12. Sano T, Sugaya T, Inoue K, Mizutaki S I, Kasai M: Cheminform abstract: process research and development of l-alanyl-I-glutamine, a component of parenteral nutrition. Chemlnform 2000, 31(39).

13. Neuh User-Berthold M, Eufinger H: Utilization of alanyl-L-glutamine and glycyl-L-glutamine during long-term parenteral nutrition in the growing rat. Amino Acids (Vienna) 1992, 3(3):293-302.

14. Yokozeki K, Hara S: A novel and efficient enzymatic method for the production of peptides from unprotected starting materials. $J$ Biotechnol 2005, 115:211-220.

15. Fields G B, Noble R L: Solid phase peptide synthesis utilizing 9-fluorenylmethoxycarbonyl amino acids. International Journal of Peptide and Protein Research 1990, 35(3): 161-214.

16. Wang M, Qi W, Yu Q, Su R, He Z: Kinetically controlled enzymatic synthesis of dipeptide precursor of L-alanyl-L-glutamine. Biotechnol Appl Biochem 2011, 58:449-455.

17. Akabori S, S Sakakibara, Y Shimonishi: Protection of amidenitrogen for peptide synthesis. A novel synthesis of peptide containing Cterminal glutamine. Bull. Chem. Soc. Jpn 1961. 34:739.

18. Li Y, Yuan W, Gao J, Fan C, Wu W, Bai F: Production of l-alanyl--glutamine by recycling $E$. coli expressing alpha-amino acid ester acyltransferase. Bioresour Technol 2017, 245:1603-1609.

19. Tanaka T, Takagi K, Saddam HM, Takeda Y, Wakayama M: Purification and characterization of Elizabethkingia L-amino acid esterase: an enzyme useful for enzymatic synthesis of the dipeptide, Valyl-Glycine. Appl Biochem Biotechnol 2017, 183:362-373.

20. Tabata K, Hashimoto S: Fermentative production of L-alanyl-L-glutamine by a metabolically engineered Escherichia coli strain expressing L-amino acid alpha-ligase. App/ Environ Microbio/ 2007, 73:6378-6385.

21. Lutz W, Jazdzewski B: Degradation of intracellular proteins. Pol Tyg Lek 1980, 35(33): 1275-1278.

22. Smith M W, Tyreman D R, Payne G M, Marshall N J, Payne J W: Substrate specificity of the periplasmic dipeptide-binding protein from Escherichia coli: experimental basis for the design of peptide prodrugs. Microbiology 1999, 145 ( Pt 10)(10): 2891.

23. Jiang P, Ninfa A J: Escherichia coli PII signal transduction protein controlling nitrogen assimilation acts as a sensor of adenylate energy charge in vitro. Biochemistry 2007, 46(45):12979-96.

24. Jaggi, R: The two opposing activities of adenylyl transferase reside in distinct homologous domains, with intramolecular signal transduction. EMBO (European Molecular Biology Organization) Journal 1997, 16(18):5562-5571.

25. Pahel G, Tyler B: A new gInA-linked regulatory gene for glutamine synthetase in Escherichia coli. Proc Natl Acad Sci U S A 1979, 76:4544-4548.

26. Brown G, Singer A, Proudfoot M, Skarina T, Kim Y, Chang C: Functional and structural characterization of four glutaminases from Escherichia coli and bacillus subtilis. Biochemistry 2008, 47(21): 5724-35.

27. Espah Borujeni A, Channarasappa AS, Salis HM: Translation rate is controlled by coupled trade-offs between site accessibility, selective RNA unfolding and sliding at upstream standby sites. Nucleic Acids Res 2014, 42:2646-2659.

28. Espah Borujeni A, Salis HM: Translation initiation is controlled by RNA folding kinetics via a ribosome drafting mechanism. J Am Chem Soc 2016, 138:7016-7023.

29. Espah Borujeni A, Cetnar D, Farasat I, Smith A, Lundgren N, Salis HM: Precise quantification of translation inhibition by mRNA structures that overlap with the ribosomal footprint in N-terminal coding sequences. Nucleic Acids Res 2017, 45:5437-5448.

30. Yokozeki K, \& Hara S: A novel and efficient enzymatic method for the production of peptides from unprotected starting materials. Journal of Biotechnology 2005, 115(2): 211-220.

31. Hayashi M, Tabata K, Yagasaki M, Yonetani Y: Effect of multidrug-efflux transporter genes on dipeptide resistance and overproduction in Escherichia coli. FEMS Microbiol Lett 2010, 304:12-19.

32. Yokozeki K, Hara S: A novel and efficient enzymatic method for the production of peptides from unprotected starting materials. Journal of Biotechnology 2005, 115(2):211-220. 
33. Hirao Y, Mihara Y, Kira I, Abe I, Yokozeki, K: Enzymatic production of L-Alanyl-L-glutamine by recombinant E. coli expressing a-amino acid ester acyltransferase from Sphingobacterium siyangensis. Journal of the Agricultural Chemical Society of Japan 2013, 77(3):618623.

34. Gibson DG, Young L, Chuang RY, Venter JC, Hutchison CA, Smith HO: Enzymatic assembly of DNA molecules up to several hundred kilobases. Nat Methods 2009, 6:343-345.

35. Ran FA, Hsu PD, Wright J, Agarwala V, Scott DA, Zhang F: Genome engineering using the CRISPR-Cas9 system. Nat Protoc 2013, 8:2281-2308.

36. Studier F W: Protein production by auto-induction in high-density shaking cultures. Protein Expr Purif 2005, 41(1): $207-234$.

37. Lin B, Tao Y: Whole-cell biocatalysts by design. Microb Cell Fact.2017, 16:106.

38. Tabata K, Ikeda H, Hashimoto S: ywfE in Bacillus subtilis codes for a novel enzyme, L-amino acid a-ligase. J Bacteriol 2005, 187:51955202.

39. Abouhamad W N, Manson M D: The dipeptide permease of Escherichia coli ciosely resembies other bacterial transport systems and shows growth-phase-dependent expression. Molecular Microbiology 1994, 14.

Figures

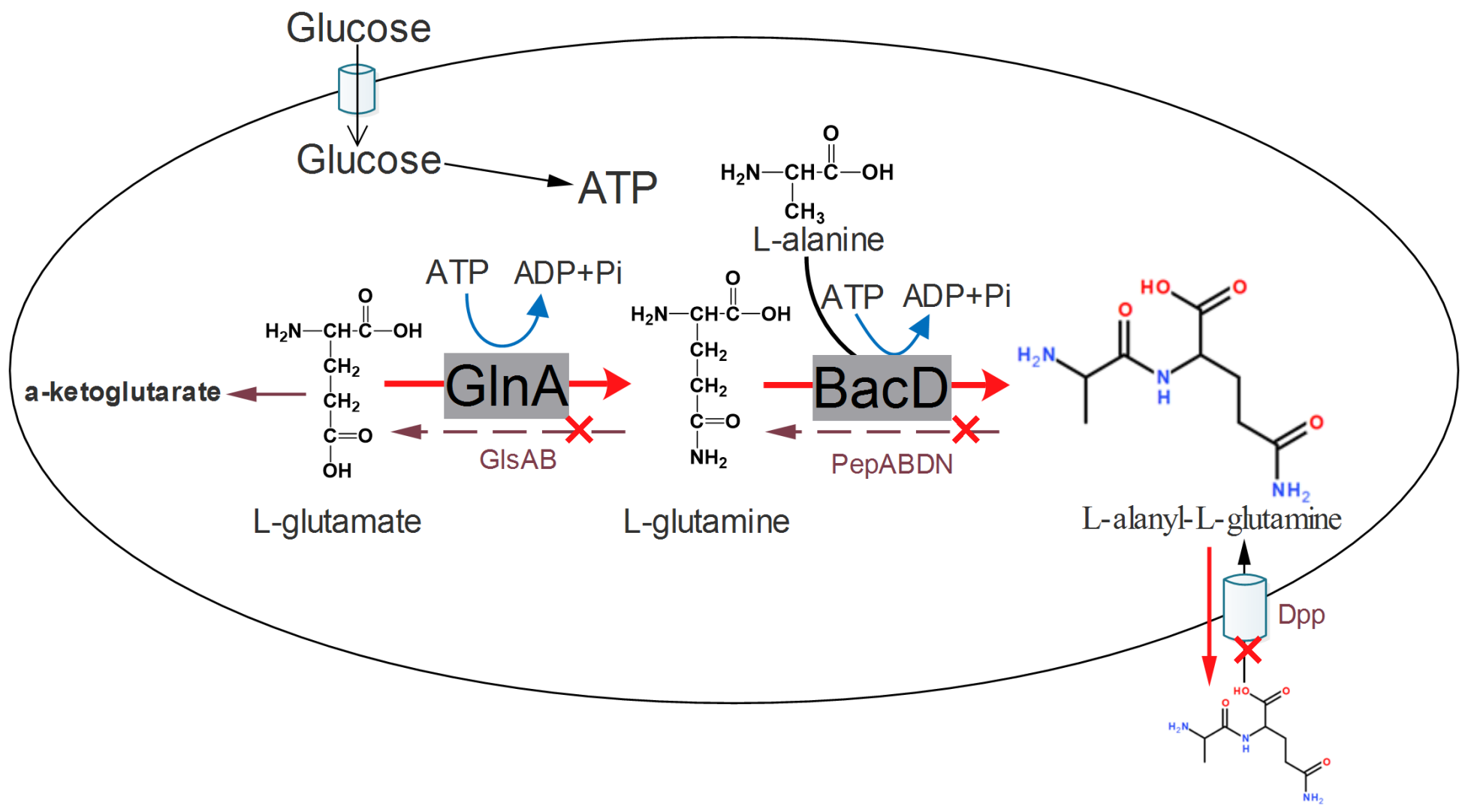

Figure 1

Schematic presentation of the AQ metabolic pathway in engineered $E$. coli. The gInA and bacD genes were co-expressed. Discontinued arrows represent the enzymatic activities that have been eliminated. GIsA, glutaminase 1; GlsB, glutaminase 2; GInE, fused glutamine synthetase deadenylase/adenylyltransferase; GlnB, nitrogen regulatory protein PII-1; PepA, aminopeptidase A/l; PepB, aminopeptidase B; PepD, peptidase D; PepN, aminopeptidase N; Dpp, dipeptide ABC transporter DppABCDF. 


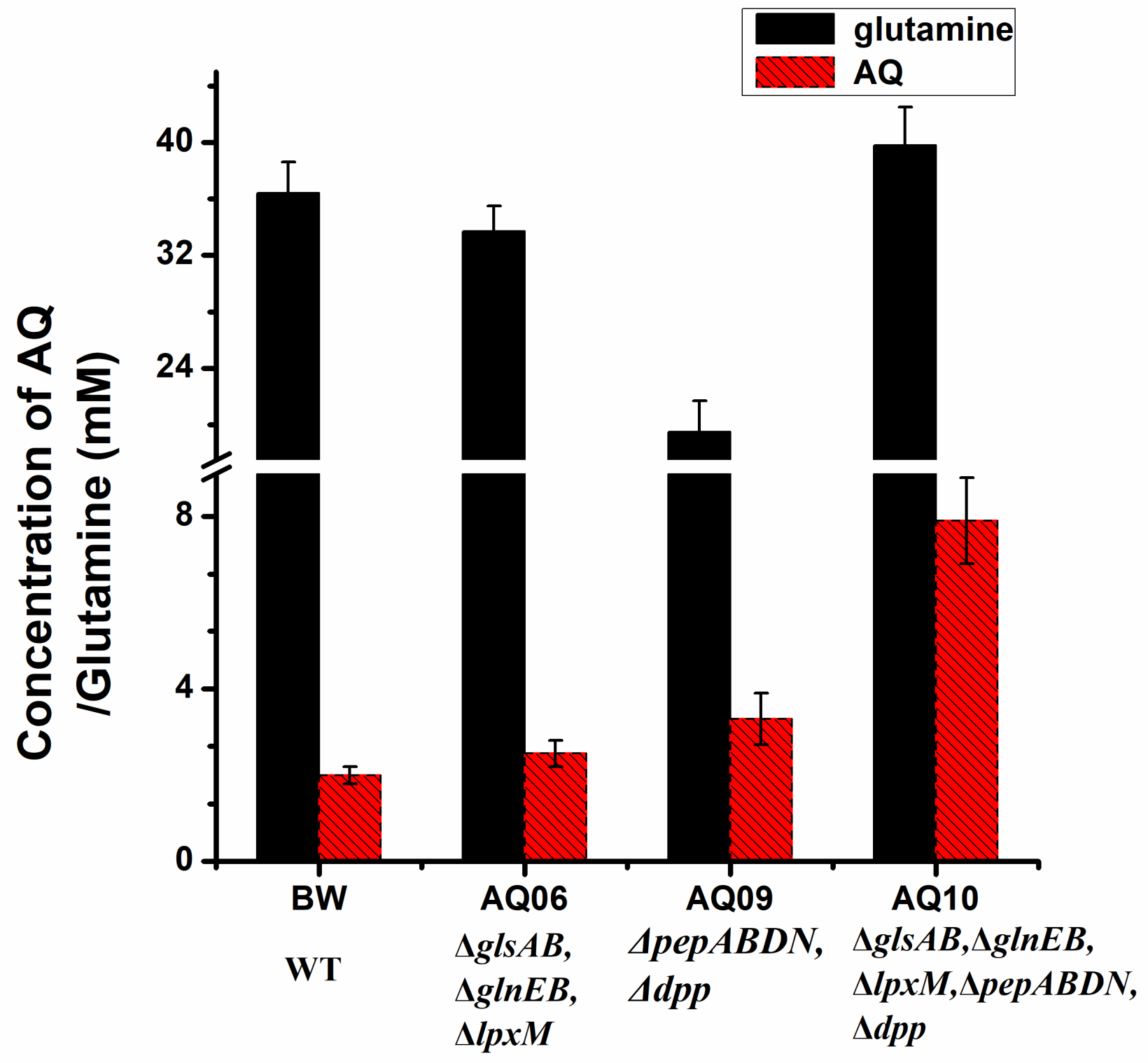

Figure 2

Extracellular titers of AQ produced by engineered strains overexpressing BsBacD. WT, wild type; BW, AQ06, AQ09, AQ10 were transformed with plasmid p01. The engineered strains were induced and suspended in a reaction mixture containing $50 \mathrm{mM}$ glutamine, $50 \mathrm{mM}$ alanine, and $10 \mathrm{mM}$ magnesium chloride. The bioconversion reactions were performed at $37^{\circ} \mathrm{C}$ and $200 \mathrm{rpm}$ for $18 \mathrm{~h}$. Glucose was supplemented at a concentration of $10 \mathrm{mM}$ every three hours. 


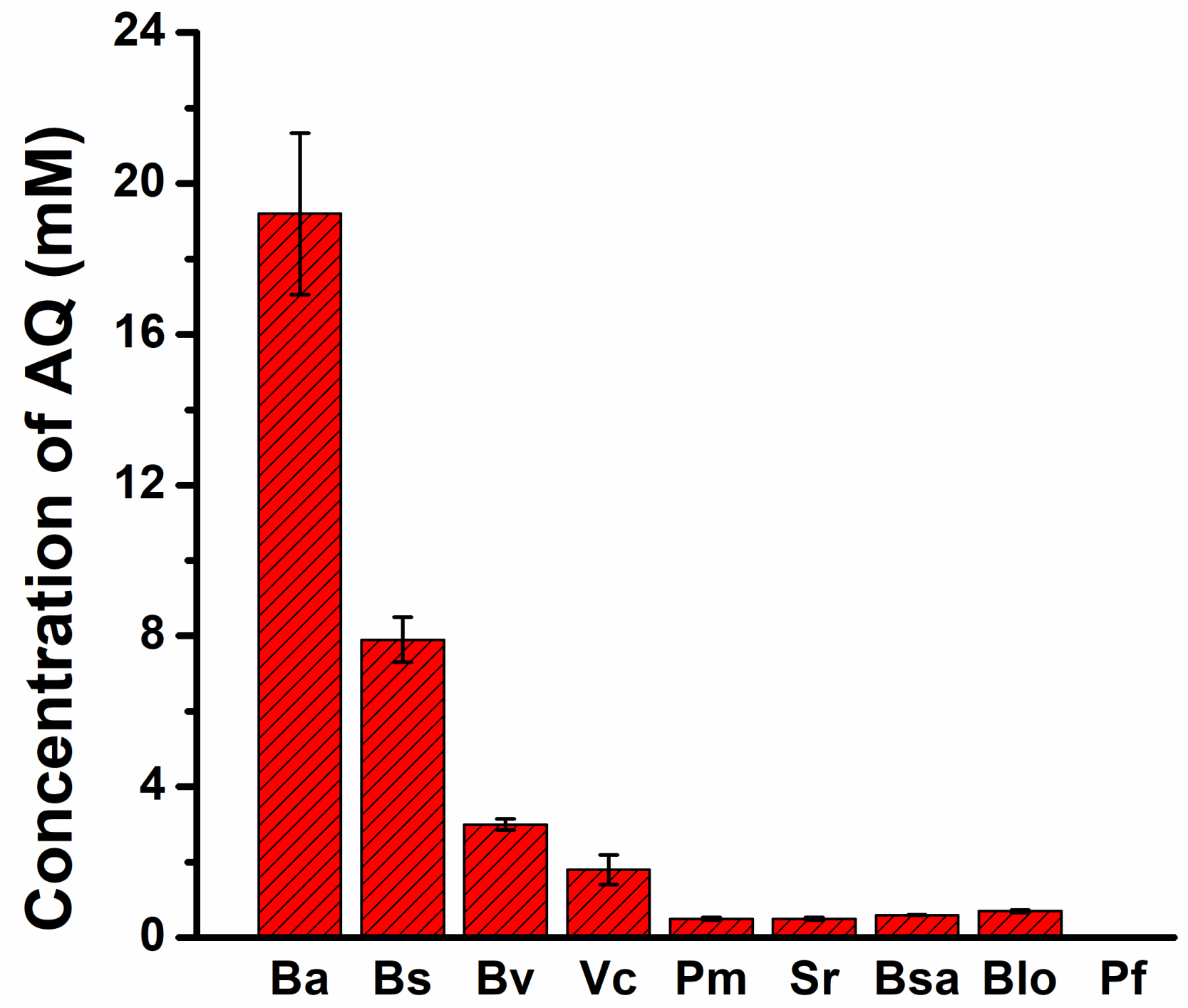

Figure 3

$A Q$ production by engineered strains over-expressing $B a c D$ homologs from different species. $B a, B a c D$ from Bacillus altitudinis; $B s, B a c D$ from Bacillus subtilis; Bv, BacD from Beta vulgaris; Vc, BacD from Vibrio campbellii; Pm, BacD from Perkinsus marinus; $S r, B a c D$ from Streptomyces rubrolavendulae; Bsa, BacD from Bacillus safensis; Blo, BacD from Bifidobacterium longum subsp. Infantis; Pf, BacD from Pseudomonas fluorescens. 


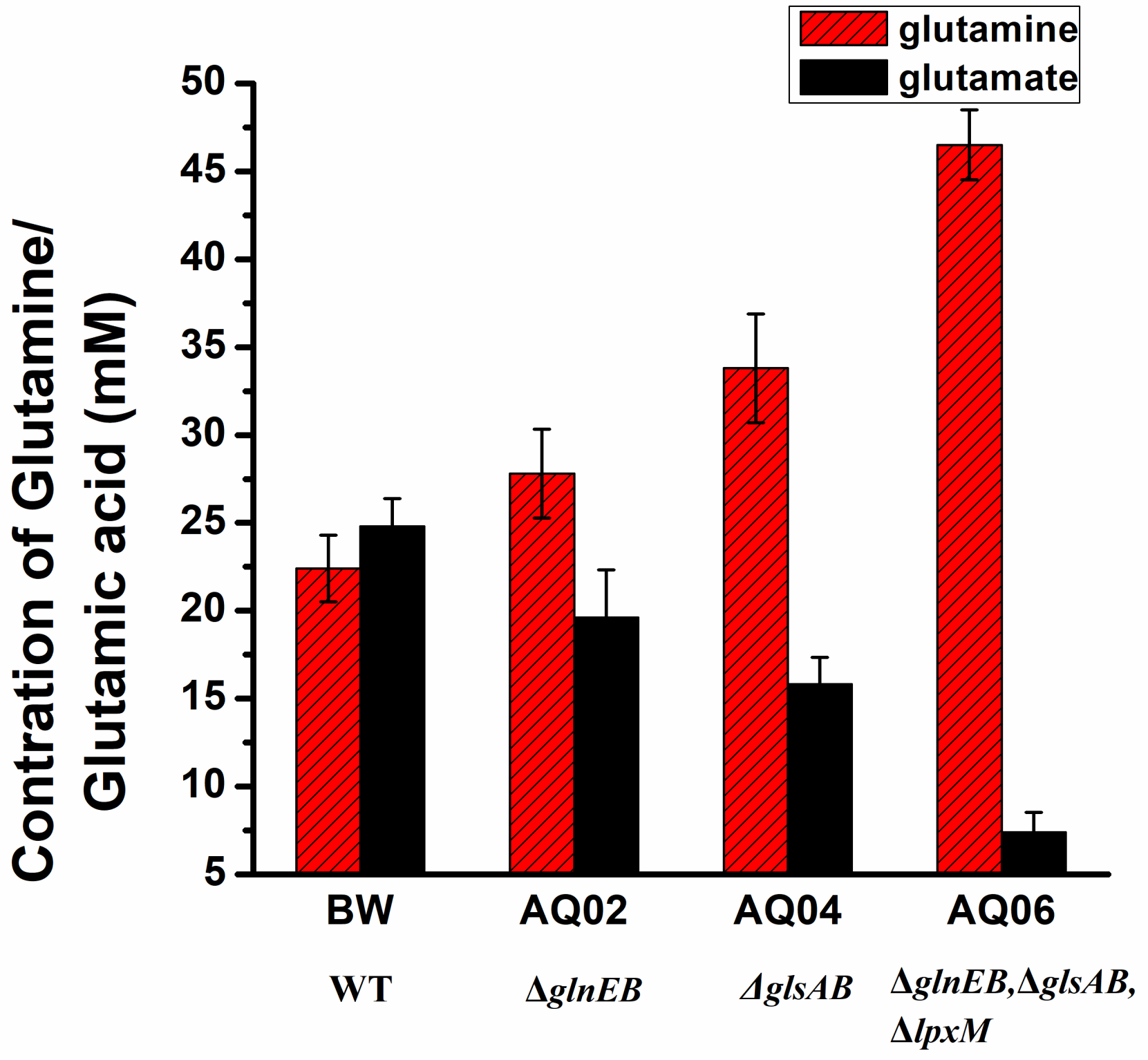

Figure 4

Extracellular glutamine titers produced by engineered strains overexpressing GInA. WT, wild type; BW, AQ02, AQ04, and AQ06 were transformed with plasmid p00. The engineered strains were induced and suspended in a reaction mixture containing $50 \mathrm{mM}$ sodium glutamate, $10 \mathrm{mM}$ magnesium chloride, and $100 \mathrm{mM}$ ammonium chloride. The bioconversion reactions were performed at $37^{\circ} \mathrm{C}$ and 200 rpm for $18 \mathrm{~h}$. Glucose was supplemented at a concentration of $10 \mathrm{mM}$ every three hours. 


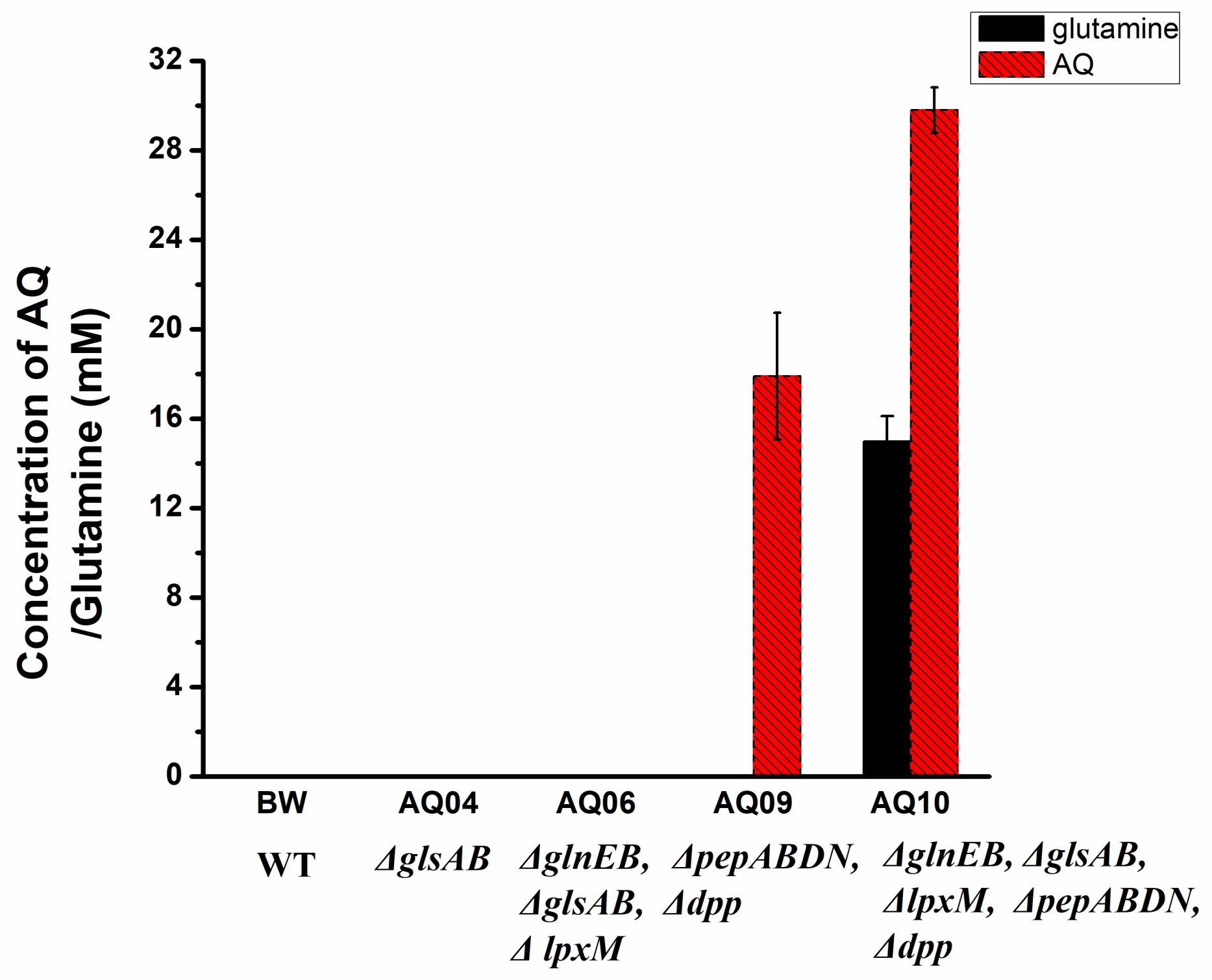

Figure 5

Production of $A Q$ by engineered strains co-expressing $C g G \ln A$ and $B s B a c D$. WT, wild type; BW, AQ02, AQ04, and AQ06 were transformed with plasmid $\mathrm{p} 11$. The engineered strains were induced and suspended in a reaction mixture containing $100 \mathrm{mM}$ sodium glutamate, 100 $\mathrm{mM}$ alanine, $200 \mathrm{mM}$ ammonium chloride, and $10 \mathrm{mM}$ magnesium chloride. The bioconversion reactions were performed at $37^{\circ} \mathrm{C}$ and 200 rpm for $18 \mathrm{~h}$. Glucose was supplemented at a concentration of $10 \mathrm{mM}$ every three hours. 

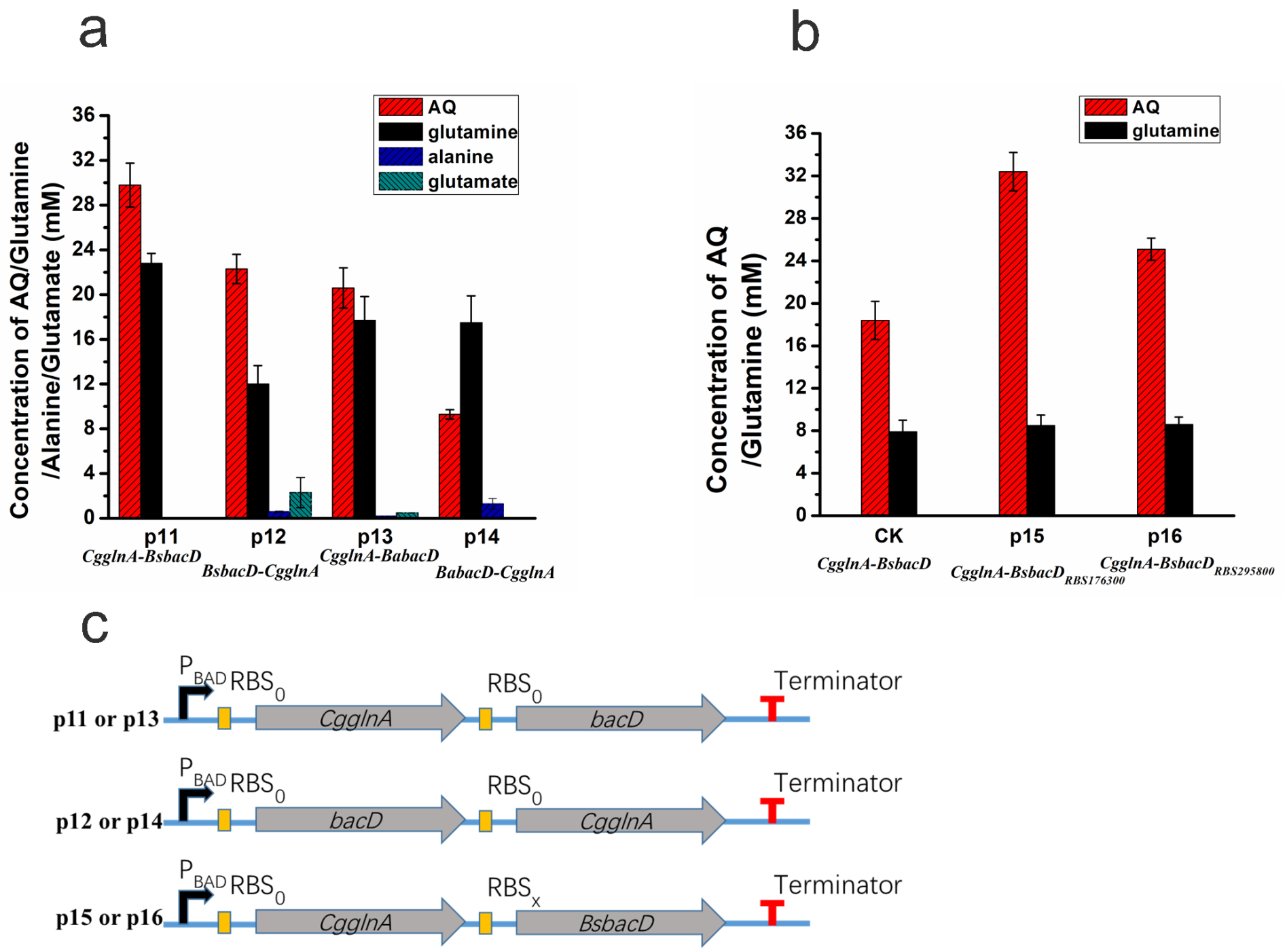

\section{Figure 6}

Regulation of the two synthesis modules by balancing the protein expression. a Production of $A Q$ in whole-cell bioconversions using engineered strains with bacD and CgglnA expressed different order. The abbreviations are: p11, pYB1s-CgglnA-BsbacD; p12, pYB1sBsbacD-CgglnA; p13, pYB1s-CgglnA-BabacD; p14, pYB1s-BabacD-CgglnA. p11, p12, p13, and p14 were individually introduced into strain AQ10. The engineered strains were induced and suspended in a reaction mixture containing $100 \mathrm{mM}$ sodium glutamate, $100 \mathrm{mM}$ alanine, $200 \mathrm{mM}$ ammonium chloride, and $10 \mathrm{mM}$ magnesium chloride. The bioconversion reactions were performed at $37^{\circ} \mathrm{C}$ and $200 \mathrm{rpm}$ for 18 h. $b$ Extracellular AQ titer produced by strains with different RBS in the front of BsbacD CDS. The reaction was performed in a reaction mixture containing $100 \mathrm{mM}$ sodium glutamate, and $100 \mathrm{mM}$ alanine for $6 \mathrm{~h}$. CK, p11/AQ10. c Modular expression of CgglnA and bacD genes in different order in a ara-operon configuration. 
a
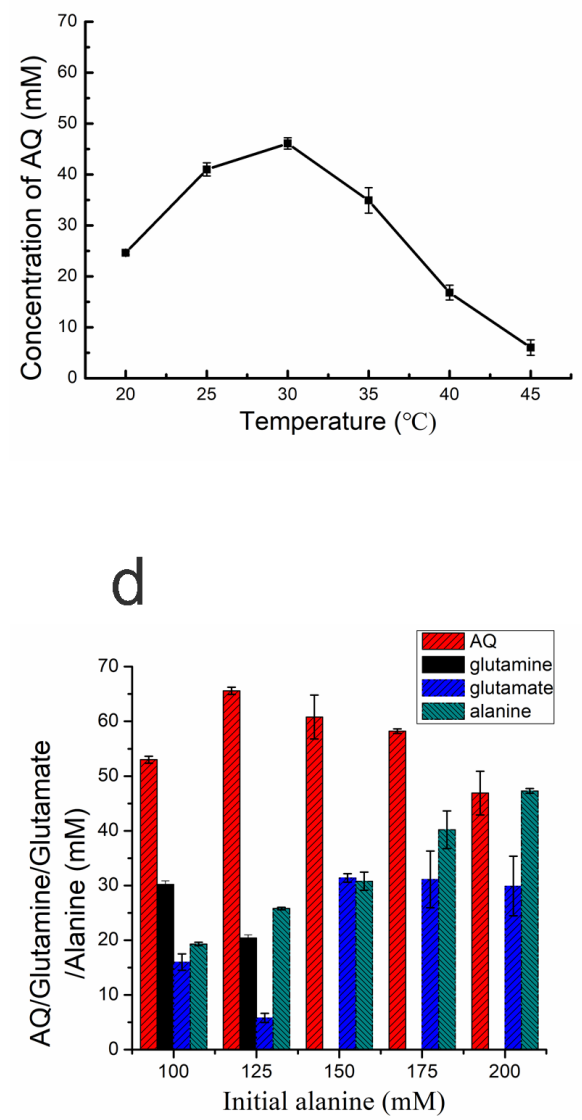

b

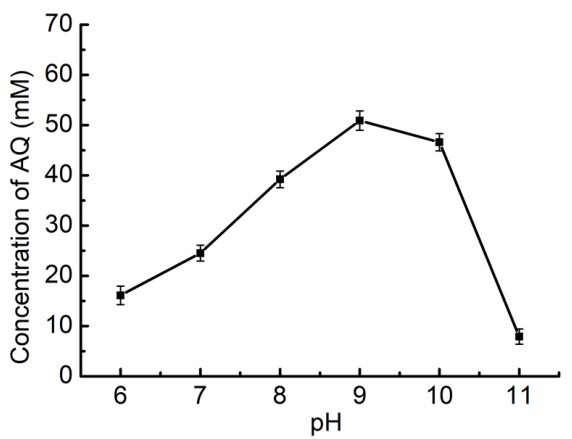

C

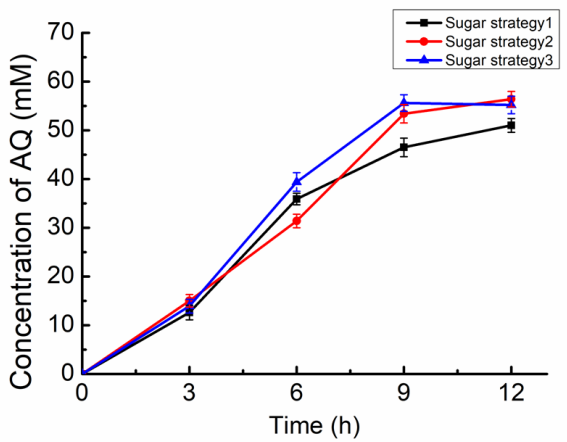

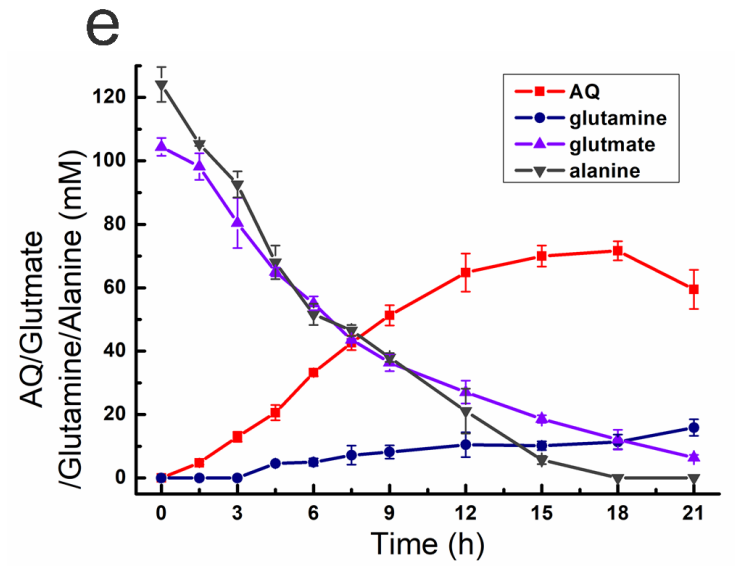

Figure 7

Optimization of the conditions for whole-cell biocatalysis. a Effects of $\mathrm{pH}$ on $\mathrm{AQ}$ production by strain $\mathrm{p} 15 / \mathrm{AQ} 10$. $\mathrm{b}$ Effects of temperature on AQ production by $\mathrm{p} 15 / \mathrm{AQ} 10$. c Effects of different glucose feeding strategies on AQ production. Feeding strategy: 1) $50 \mathrm{mM}$ glucose was added at once; 2) $10 \mathrm{mM}$ glucose was added every 3 hours; 3) $20 \mathrm{mM}$ glucose was added every 3 hours. d Effects of the initial alanine concentration on AQ production. Initial alanine concentrations of 100-200 mM were combined with a fixed glutamic acid concentration at $100 \mathrm{mM}$, and the reaction was performed for $12 \mathrm{~h}$. e Time profiles of the AQ, glutamine, glutamic acid and alanine concentrations. The bioconversion was performed in a reaction mixture containing $100 \mathrm{mM}$ sodium glutamate, $125 \mathrm{mM}$ alanine, $200 \mathrm{mM}$ ammonium chloride, and $10 \mathrm{mM}$ magnesium chloride at $30^{\circ} \mathrm{C}$ and $\mathrm{pH} 9.0$.

\section{Supplementary Files}

This is a list of supplementary files associated with this preprint. Click to download.

- Graphicalabstract.docx

- Supplementalmaterial.docx 